\title{
Chapter 11 \\ Breeding New Aromatic Rice with High Iron Using Gamma Radiation and Hybridization
}

\author{
Phuong Tan Tran and Cua Quang Ho
}

\begin{abstract}
The goal of many breeding programmes is the combination of several improved traits to produce a cultivar that meets demands of farmer and consumer. For example, breeding aromatic rice varieties having both high quality and yield is an objective in Vietnam to satisfy domestic consumers and increase value in the export market. Genetic variation is the starting point for any breeding programme. In some cases sufficient variation exists and traditional hybridizations and introgressions are suitable for cultivar development. In other cases, new variation, such as that created through mutagenesis, is required for the development of new traits. Thus, a combinatorial approach using both hybridization and induced mutations can be considered when the goal is a new cultivar expressing several improved traits. We have taken this approach in rice breeding to generate lines with improved aroma and high iron content. Here we provide a protocol for mutation induction, hybridization and phenotypic analysis for the improvement of aroma and iron content in rice using a combined mutation and hybridization approach. Example data from this work is shown. This approach can be easily adapted for other traits of interest.
\end{abstract}

Keywords Aroma • Badh2.1 • Bioavailable iron • Iron content • High quality • Hybridization $\bullet$ Pedigree selection

\subsection{Introduction}

There is an increasing demand for the production of high-grain-quality aromatic rice to meet the domestic demand and also for export. Though there are many aspects which impact quality, key features that influence the market value of rice are aroma, kernel shape, cooking quality and taste. Aromatic rice is unique and prized in many countries. Local aromatic rice varieties in Vietnam have high value in the domestic market. There are famous varieties such as Tao Huong, Nang Thom in the south and the Tam group (Tam Xoan, Tam Thom) in the north. These

P.T. Tran $(\bowtie) \bullet$ C.Q. Ho

Soc Trang Department of Agriculture and Rural Development, Soc Trang, Vietnam e-mail: trantanphuong2005@gmail.com 
varieties have disadvantageous traits such as photoperiod sensitivity; long growth duration (160-180 days); high stature (150-185 cm); thin, long, drooping leaves; and sparseness between grains. The consequence of these negative traits is low productivity calculated in the range of 2-3 tons/ha/crop. The advantage of these varieties is their better adaptation to the poor land and changing climatic conditions. Both genetics and environment affect traits such as aroma. For example, basmati rice loses the aroma when grown outside the Punjab in Pakistan and India. It is thought that Punjab climate and/or soil is important for producing a strong aroma (Efferson 1985). Khao Dawk Mali 105, the most important aromatic rice cultivar in Thailand, is reported to have the strongest aroma and best quality when grown in the Tung Kula Rong Hai region in northwest Thailand (Yoshihashi et al. 2004). Ideally, high-yielding, aromatic and photoperiod-insensitive varieties can be bred to serve increasing demands of customers in domestic and the world markets and to increase incomes for farmers.

The success of any breeding programme relies on genetic variation in the form of altered alleles that control or contribute to the traits of interest. There are vast genetic resources available for rice (e.g. http://irri.org/about-us/our-organization/ genetic-resources-center). Traditional breeding approaches seek to generate new combinations of alleles that result in an improved variety. Yet, some traits (alleles) may not be available in existing germplasm or available only in genotypes that are recalcitrant due to linkage drag with negative traits. New alleles can be created at a high frequency using mutagenesis (see Chap. 1). Thus mutagenesis can be considered to support breeding objectives. In some cases mutagenesis of elite cultivars can be performed and improved varieties can be directly released (see Chap. 9). This is quite common and about $62 \%$ of all officially registered mutant varieties are produced in this fashion (see Chap. 1 and MVD 2016). Hybridization of mutant alleles with "natural" alleles already present in germplasm is another approach. We provide an example of hybridization of mutant and natural alleles to produce high aroma and high bioavailable iron accessions in this chapter. The general approach for directed hybridizations is shown in Fig. 11.1.

In addition to requisite genetic variation, appropriate screening techniques are needed to produce improved varieties. For rice aroma, many researchers have examined the trait by a sensory test. Buttery et al. (1983) identified the characteristic aroma compound in steam volatile oils of cooked aromatic rice as 2-acetyl-1pyrroline (2AP). Yoshihashi (2002), by a method using isotope-labelled analogues of $2 \mathrm{AP}$, reported that the concentrations of $2 \mathrm{AP}$ are presented in milled and brown rice, rice bran, husk and seedlings. $2 \mathrm{AP}$ was not detected in root and it does not form during cooking or postharvest processing. Solid phase microextraction (SPME) has emerged as a rapid and efficient tool for the extraction and quantification of the aroma compounds (Stashenko and Martínez 2007). It is a rapid, simple, versatile and solvent-free technique and has integrated sampling, extraction, concentration and sample introduction of volatile compounds into gas chromatography (GC) in a single step resulting in high sample throughput (Soria et al. 2009; Picó et al. 2007). 


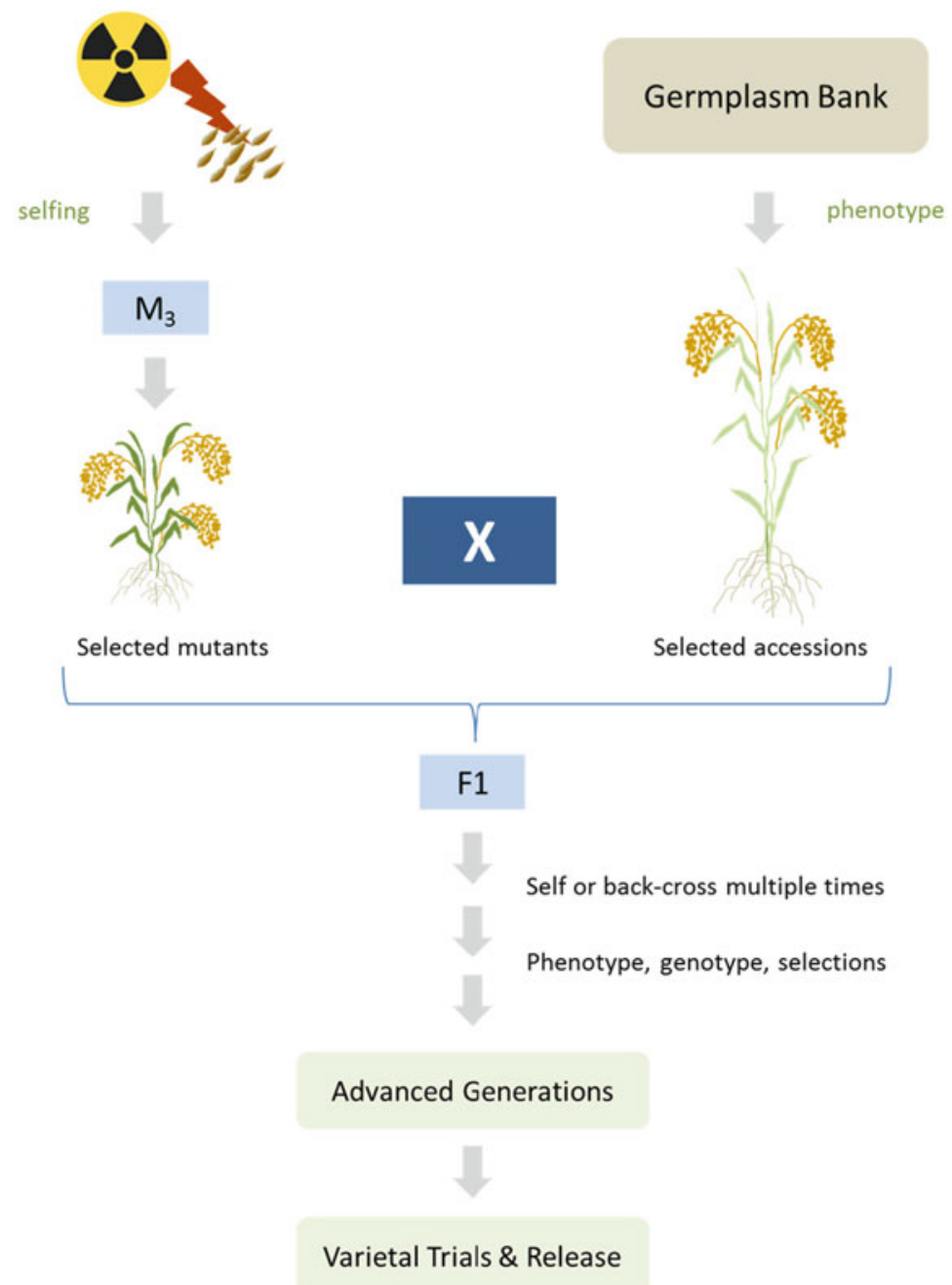

Fig. 11.1 Development of new rice cultivars through hybridization of mutant and natural alleles. Mutant populations are developed by treating seed with gamma irradiation (top left). Plants are self-fertilized and screened for improved traits. Phenotypic analysis is also carried out on accessions from a germplasm bank. Selected accessions are then hybridized with selected mutants. Since most traits will be recessive, the resulting F1 is further crossed. Different crossing strategies can be used such as selfing or backcrossing to the selected accession to introgress mutant alleles. Crossing and phenotypic analysis continues until traits are stabilized. At this time plants can be subjected to requisite varietal trials followed by eventual release. Figure courtesy of Dr Joanna Jankowicz-Cieslak and Dr Bradley J. Till of the FAO/IAEA Joint Programme

Micronutrient malnutrition, the result of diets poor in vitamins and minerals, affects more than half of the world's population. Women and children are especially susceptible to deficiencies in micronutrients, particularly vitamin A, iron and 
zinc. As a result they are at risk of disease, premature death, lower cognitive capacity and poor quality of life. Nutritionally improved staple food provides an inexpensive, cost-effective, sustainable, long-term means of delivering micronutrients to the poor. Brown rice is a more nutritious food in comparison with white rice owing to the fact that the bran layer contains high amounts of vitamin B1, plus other nutrients and micronutrients. Other important components, $\gamma$-tocotrienol and $\gamma$-oryzanol in the bran covering of brown rice, have the effect of reducing cholesterol in the blood, an important factor causing cardiovascular disease (Chen and Cheng 2006). Brown rice is also suitable for people who follow the "macrobiotic diet" which not only brings much nutrients but also has a sweet taste created by the contribution of many enzymes on sugar and proteins inside grains. Researches on iron content in brown rice samples showed that iron content changes depending on varieties, IR64 (12.58-12.88 mg/kg), Jasmine 85 (12.84-18.50 mg/kg) and OMCS2000 (11.77-14.78 mg/kg), and about $2 / 3$ of iron content is lost through milling (Tran et al. 2004). However, it is difficult to stabilize the iron content and aromatic level because iron and zinc contents vary in different regions and growing seasons (Liang et al. 2006). Based on research and evaluation of iron-enriched rice domestically and internationally, and responding to the national strategy on nutrition, we have conducted cross-breeding for iron-enriched aromatic rice varieties by using mutant materials, local aromatic varieties and improved aromatic varieties to contribute to nutrition security for households.

\subsection{Materials}

1. Rice seed from accessions with desired traits (see Note $\mathbf{1}$ and Table 11.1 for examples).

2. Rice mutant lines (see Note 2).

3. $\mathrm{KOH}$ (potassium hydroxide).

4. A cobalt-60 facility (see Note 3).

5. Scale for measuring seed weight.

6. Ruler.

7. Hygrometer.

8. Test tubes $(1.3 \times 10 \mathrm{~cm})$.

9. Dehuller (e.g. Satake).

10. Atomic absorbance spectrophotometer.

11. Taq polymerase.

12. $\mathrm{MgCl}_{2}$.

13. dNTPs.

14. Gene-specific primers. 
Table 11.1 Rice accessions with variation in aroma

\begin{tabular}{|c|c|c|c|c|c|}
\hline $\mathrm{SDK}^{\mathrm{b}}$ & $\begin{array}{l}\text { Name of Vietnamese local } \\
\text { rice variety }\end{array}$ & Aroma $^{a}$ & $\mathrm{SDK}^{\mathrm{b}}$ & $\begin{array}{l}\text { Name of Vietnamese local } \\
\text { rice variety }\end{array}$ & Aroma $^{a}$ \\
\hline \multicolumn{6}{|c|}{ Vietnamese local aromatic rice varieties } \\
\hline & Nang Thom Cho Dao & + & 5121 & Tam Con & + \\
\hline 233 & Tam Tuc Tay Bac & + & 5122 & Tam Nghia Lac & + \\
\hline 268 & Tam Den Ha Dong & + & 5124 & Tam Hai Giang & + \\
\hline 274 & Tam Ap Be Ninh Binh & + & 5126 & Tam Ap Be & + \\
\hline 314 & Tam Xoan Bac Ninh & + & 6212 & Tam Co Rut & + \\
\hline 316 & Tam Nghe Hat Do & + & 6216 & Tam Thom & + \\
\hline 5117 & Tam Xuan Dai & + & 6240 & Tam Cao Cay & + \\
\hline 5119 & Tam Xuan Hong & + & 6250 & Tam Tieu & + \\
\hline 5120 & Tam Nghia Hong & + & 2376 & Du Nghen & + \\
\hline 219 & Tam Tron Hai Duong & - & & Tam Thom Hai Hau TT1 & + \\
\hline \multicolumn{6}{|c|}{ Vietnamese improved aromatic varieties } \\
\hline & Soc Trang 3 (ST3) & + & & Soc Trang 13 (ST13) & + \\
\hline & Soc Trang 5 (ST5) & + & & Soc Trang 14 (ST14) & + \\
\hline & Soc Trang 6 (ST6) & + & & Soc Trang 15 (ST15) & + \\
\hline & Soc Trang $10($ ST10) & + & & Soc Trang 17 (ST17) & + \\
\hline & $\begin{array}{l}\text { Soc Trang } 12 \text { (ST12) } \\
\text { Huong Com } \\
\text { Hoa Sua }\end{array}$ & $\begin{array}{l}+ \\
+ \\
+\end{array}$ & & Soc Trang 18 (ST18) & + \\
\hline
\end{tabular}

Rice control

\begin{tabular}{l|l|l|l|l|l}
\hline & Jasmine 85 & + & & & \\
\hline & Khao Dawk Mali 105 & + & & VND95-20 & - \\
\hline
\end{tabular}

a $(+)$ aroma, (-) non-aroma

${ }^{\mathrm{b}} \mathrm{SDK}$ : seed bank number

\subsection{Methods}

\subsubsection{Preparing a Mutant Population}

1. Irradiate seed (see Note 4).

2. Sow seed in a field nursery.

3. Transplant mutant plants to an experimental field after 25 days nursery growth.

4. Propagate material until the $\mathrm{M}_{3}$ generation (see Note 5).

5. Begin phenotypic evaluation in the $\mathrm{M}_{3}$ generation (see Note 6 ).

6. Select interesting plants for further characterization and hybridization (see Note 7).

7. Continue phenotypic evaluations (see Note 7). 


\subsubsection{Phenotypic Analysis of Aroma}

1. Harvest seed when $90 \%$ in panicles are ripe. Note that $\mathbf{M}_{1}$ plants from seed mutagenized material is not suitable for phenotypic analysis as it is chimeric.

2. Air-dry until humidity reaches $14 \%$.

3. Dehull seed from individual plants.

4. Combine 40 seeds and $5 \mathrm{ml} 1.7 \% \mathrm{KOH}$ in a test tube.

5. Cover tube and let stand for $15 \mathrm{~min}$ at room temperature.

6. Evaluate aroma by smell (see Note 8).

\subsubsection{Genotypic Analysis of Aroma}

1. Extract genomic DNA from selected material (see Note 9).

2. Design primers for a PCR-based marker assay (see Note 10).

3. Combine $0.25 \mu \mathrm{l}$ Taq DNA polymerase, $1 \mu \mathrm{l}$ of genomic DNA, $2.5 \mu \mathrm{l}$ of $10 \times$ buffer, $3 \mathrm{mM} \mathrm{MgCl} 2,4 \mu \mathrm{l}$ of dNTPs and $2.0 \mu \mathrm{l}$ of each primer in a total volume of $25 \mu$ l.

4. Incubate samples: $94{ }^{\circ} \mathrm{C}$ for $2 \mathrm{~min}$ followed by 35 cycles of $5 \mathrm{~s}$ at $95{ }^{\circ} \mathrm{C}, 5 \mathrm{~s}$ at $58^{\circ} \mathrm{C}$ and $5 \mathrm{~s}$ at $72{ }^{\circ} \mathrm{C}$, concluding with a final extension of $72{ }^{\circ} \mathrm{C}$ for $5 \mathrm{~min}$.

5. Analyse PCR products using a $2 \%$ agarose gel containing $0.5 \times \mathrm{TBE}$ (see Note11).

\subsubsection{Chromatographic Analysis of Aroma Compounds}

1. Place $3.5 \mathrm{~g}$ of milled rice with $500 \mu \mathrm{l}$ of water in a $10 \mathrm{ml}$ vial (see Note 12).

2. Equilibrate samples at $80{ }^{\circ} \mathrm{C}$ for $5 \mathrm{~min}$.

3. Introduce a Supelco ${ }^{\circledR} \mathrm{VB} / \mathrm{Carboxen} / \mathrm{PDMS}$ (divinylbenzene/Carboxen/ polydimethylsiloxane) fibre in the headspace surrounding the rice at the same temperature for $15 \mathrm{~min}$ for solid phase microextraction (SPME) of aroma compounds.

4. Analyse extracts using a Hewlet Packard 5890 Série II gas chromatograph using a non-polar DB-5 (J\&W Scientific) capillary column (length $60 \mathrm{~m}, 0.32 \mathrm{~mm}$, film thickness $0.25 \mu \mathrm{m})$.

5. Use helium as a carrier gas at a flow rate of $1.9 \mathrm{ml} \mathrm{min}^{-1}$ at $25^{\circ} \mathrm{C}$.

6. Perform injection in splitless mode first ( $5 \mathrm{~min}$ for SPME), then in split mode to the end of the cycle (38.5 min for SPME).

7. Warm the column at $40{ }^{\circ} \mathrm{C}$ for $5 \mathrm{~min}$, then apply the following temperature programmes for SPME: from 40 to $115^{\circ} \mathrm{C}$ at a rate of $3{ }^{\circ} \mathrm{C} / \mathrm{min}$, then from 115 to $220{ }^{\circ} \mathrm{C}$ at $30{ }^{\circ} \mathrm{C} / \mathrm{min}$, and finally maintain at $220{ }^{\circ} \mathrm{C}$ for $5 \mathrm{~min}$.

8. Maintain the detector port at $250^{\circ} \mathrm{C}$. 
9. Calculate 2AP from the area ratio between 2AP's peak and the internal standard (see Sect. 11.5 for example data).

\subsubsection{Combination of Traits Through Hybridization}

1. Select materials for crossing (see Note 13).

2. Perform crosses to generate $F_{1}$ material.

3. Perform phenotypic evaluation of $F_{1}$ material (see Note 14).

4. Self-fertilize material to produce a segregating $\mathrm{F}_{2}$ population.

5. Begin phenotypic and genotypic evaluations and selections to choose material for further propagation.

6. Continue propagation for several cycles (e.g. $\mathrm{F}_{11}$ ) to ensure that traits are fixed and pure bred (see Fig. 11.1 and Sect. 11.5.1 crossing schemes to combine and fix traits in rice).

\subsection{Notes}

1. It is good practice to choose, when available, multiple accessions having similar traits. This material will be used in hybridizations with mutant lines. Having a diverse set of starting material diversifies the alleles for introgression and should increase the chances of success. In the example, 20 Vietnamese local aromatic rice varieties that were tall, bold grain shape and short-day length photoperiod sensitive were chosen. They have had hard texture when cooked and the average yield is approximately 3-4 tons/ha. Nine aromatic ST rice varieties and Hoa Sua, Huong Com have growth duration of 105-115 days, improved phenotype with 5-6 ton/ha yield and high-quality grain length 7.5-7.8 mm, slender grain, non-chalkiness of endosperm and amylose content of $17-19 \%$.

2. Seed for irradiation should be homogeneous and crossable with the other accessions chosen. In the example provided in this protocol, Zazu and Huyet Rong, a wild-type, tall and photoperiod-insensitive variety, was selected. The average yield is approximately 3-4 tons/ha. This is a local aromatic variety specific to Vietnam, having hard texture when cooked, aroma, long grains, dark-red bran layer and purple-yellow husk.

3. Other sources of gamma irradiation such as caesium and other types of mutagenesis such as X-ray irradiation and also chemical mutagenesis can be used. It is important that the mutagenic treatment is optimized.

4. The procedure to obtain the mutants may be summarized as follows: Seeds of Zazu and TT1 were incubated in a water bath at $33{ }^{\circ} \mathrm{C}$ for $48 \mathrm{~h}$ to induce germination to obtain high-frequency gene mutation. They were then irradiated by gamma-rays from a ${ }^{60} \mathrm{Co}$ facility at two doses: $12 \mathrm{krad}(120 \mathrm{~Gy})$ and $15 \mathrm{krad}$ 
(150 Gy). After $24 \mathrm{~h}$, the seeds were sown in a field nursery to obtain the first generation $\left(\mathrm{M}_{1}\right)$. Phenotypic selections began at the $\mathrm{M}_{3}$ generation selected by staff Le Xuan Tham and Nguyen Thi Thu Hien.

5. A bulking procedure can be used until interesting phenotypes are identified. At this point a pedigree approach should be taken whereby mutations are fixed. Individuals are propagated through self-fertilization, and phenotypes are evaluated and selected at each generation to develop pure-bred lines. In our work we carried mutant lines to $\mathrm{M}_{10}$ and hybridized material to $\mathrm{F}_{11}$. Further description of creating pure-bred material from initially bulked material is described in Chap. 9.

6. In addition to specific traits of interest, it is useful to collect data on general traits. Data on plant height $(\mathrm{cm})$, number of effective tillers/plant, panicle length $(\mathrm{cm})$, number of filled grains/panicle, 1000 seed weight (gr), days to maturity and grain yield (ton/ha) were recorded in our example. After harvesting, the seeds of each genotype were dehulled for evaluation of the grain quality, viz. grain size (grain length), grain shape (grain length-breadth ratio) and also aroma. In addition, in our work analysis for bioavailable iron was conducted by atomic absorbance spectrophotometer (AAS) method and the related methods at Da Lat Nuclear Research Institute. See Sect. 11.5 for example data.

7. It is useful to phenotypically characterize accessions prior to using in hybridizations to ensure plants actually show the desired traits. For example, in our work we chose to perform analysis for bioavailable iron conducted by atomic absorbance spectrophotometer (AAS) method and the related methods at Da Lat Nuclear Research Institute. See Sect. 11.5 for example data. Analysis of mutant plants can continue until desired mutant traits are found. During the early stages of propagation (e.g. $\mathrm{M}_{3}$ ), there is a chance that other mutations (alleles) are co-segregating and epistatic interactions may limit the ability to identify plants with interesting traits. As propagation proceeds, alleles should segregate away from each other and phenotypes stabilize. At some point the chance of finding new traits is low. We typically do not carry observations past the 11 th generation.

8. The detection of fragrance can be carried out via sensory or chemical methods, although each has their disadvantages. Chemical methods involving smelling leaf tissue or grains after heating in water or reacting with solutions of $\mathrm{KOH}$ (Sood and Sidiq 1978) can cause damage to the nasal passages. Sensory methods therefore have their limitations when processing large numbers of samples, but it gives results in a shorter time and at lower costs for the rice breeder. Aroma evaluation by smell is subjective. It is ideal to select a group of people for the evaluation and average the scores. For example, there were five people in our testing team, they smelled at well-aired places and classified the aroma by four groups: strongly aromatic (score 7), moderately aromatic (score 5 ), lightly aromatic (score 3) and non-aromatic (score 1). The score of one sample is the average score of three repeated times of smelling, each time is 10 min apart. It is useful to include control material known to have good aroma 
and control material known to have poor aroma when performing subjective sensory methods.

9. Methods for low-cost extraction of genomic DNA are described in Chap. 14.

10. Molecular markers may have been developed for traits arising from natural alleles that have spread in populations through evolution and breeding. In the case of rice aroma, the accumulation of $2 \mathrm{AP}$ in aromatic rice is explained by the loss of function mutations in the badh2 gene (Bradbury et al. 2005; Chen et al. 2008). At least ten non-functional alleles of the badh 2 gene have now been identified (Shi et al. 2008; Sakthivel et al. 2009; Kovach et al. 2009). We used this data to develop four primer sets to evaluate aroma markers in varieties from Vietnam using a simple PCR assay to evaluate differences in amplicon mobility (see Sect. 11.5). It is important to note that this approach is inefficient and difficult when evaluating new alleles created by mutation because newly induced mutations did not previously exist in the population and could be in any gene or regulatory region. To create markers for mutant alleles, the best approach is traditional mapping/cloning or through the aid of genome sequencing (see Chap. 1).

11. Suitable primer combinations show clearly different band mobilities. Higherresolution gels such as polyacrylamide can be used when agarose is insufficient.

12. For samples analysed by SPME-GC, collidine was added as an internal standard.

13. It is best to choose well-characterized materials for hybridization.

14. This is important when using mutant material to confirm if alleles are dominant or recessive. If desired combinations of traits are observed in the $F_{1}$, one can consider doubled haploid approaches to instantly fix alleles. Doubled haploidy (DH) can also be applied in the $\mathrm{F}_{2}$ or later generations. Chapter 16 of this book provides a protocol on validation of putatively $\mathrm{DH}$ plants.

\subsection{Example Data}

\subsubsection{Breeding New Aromatic Rice in High Bioavailable Iron by Using Gamma Radiation and Crossing}

\subsubsection{Results of Aroma Testing by Sensory from $M_{3}$ to $M_{10}$ Generations}

We selected dark-red bran layer rice grains and tested aroma in rice. Results of line choice and aroma testing by sensory from $\mathbf{M}_{3}$ to $\mathrm{M}_{10}$ generations (Table 11.2) showed that the rate of strong aroma increased from 8.22 to $12 \%$ and aromatic lines of total aroma tested lines increased correlatively from 30.14 to $60 \%$, and the mean aroma score of populations increased from 3.55 to 4.68 . From $\mathrm{M}_{3}$ we got $5311 \mathrm{M}_{3}$ plants (Table 11.2). From this, $111 \mathrm{M}_{3}$ plants were chosen for testing aroma. 
Non-aromatic lines fluctuated from $35.14 \%$ in the $\mathrm{M}_{3}$ generation to $8.61 \%$ in $\mathrm{M}_{5}$ generation; therefore, average aroma score of the population continuously increased after each generation. From seventh to tenth generations, there were no non-aromatic lines and five strong aromatic lines were selected in $\mathrm{M}_{10}$. These strong aromatic lines were planted consecutively and without replications to evaluate several agronomic criteria such as length of flag leaf, length of dynamic leaf, panicle length, number of tillers/hill and panicles/hill, hypothetical yield and actual yield. External characteristics such as grain length, grain width, grain shape and zero-score chalkiness of endosperm indicated that zero-score chalkiness of endosperm of these mutant rice lines fluctuates from 65.2 to $78.1 \%$ and long and slender grains (ratio of length to width was 3.2-3.4), so these lines have nice grain shape and good quality and value. They have low gelatinization temperature, medium gel consistency and amylose content between 17.3 and $21.1 \%$; therefore, they are classified as soft rice which is still soft over $24 \mathrm{~h}$ after cooking. Moreover, they have long-lasting aroma and strong aroma. Comparing evaluated characteristics including the growth duration time (105 days) and bioavailable iron content, we chose two new aromatic rice varieties named as Red 06 (from $12 \mathrm{krad}$ irradiation dosage) and Red 156 (from 15 krad irradiation dosage). Bioavailable iron content of Red 06 and Red 156 are $44.4 \mathrm{ppm}$ and $35 \mathrm{ppm}$, while bioavailable iron content of Zazu is $19.5 \mathrm{ppm}$.

\subsubsection{Hybridizations to Create High Aroma and Iron Rice}

The availability of the rice mutant resource is already helping researchers in their quest to gain insights into the biology of this commercially important crop. These efforts are critical to understand gene function and breeding. Some promising mutant rice lines are discovered, but some characters need to be modified. Therefore we elaborated a strategy in which we use these promising mutant rice lines for crossing with other rice varieties (e.g. Fig 11.2).

Results of lines chosen and aroma testing (Table 11.3) showed that the rate of slightly aromatic and non-aromatic lines was high at early generations, and it gradually decreased until traits were fixed in selected lines.

Nine strongly aromatic lines which were selected were also taken for analysis for bioavailable zinc and bioavailable iron contents by AAS method (Table 11.4). The results showed that zinc content of the nine lines is the same as that of existing inbred varieties.

\subsubsection{Further Hybridizations to Combine Traits}

In the scope of this research, we selected four different parental lines for breeding. Parental lines selected for breeding were evaluated for their agronomic and quality traits. The results are shown in Tables 11.5 and 11.6. 
Table 11.2 The result of aromatic lines selected over segregating generations

\begin{tabular}{|c|c|c|c|c|c|c|c|c|c|c|}
\hline \multirow[b]{2}{*}{$\mathrm{G}^{\mathrm{a}}$} & \multirow{2}{*}{$\begin{array}{l}\text { Lines used } \\
\text { for aroma } \\
\text { testing }\end{array}$} & \multicolumn{8}{|c|}{ Aromatic scale } & \multirow{2}{*}{$\begin{array}{l}\text { Mean aroma of } \\
\text { populations } \\
\text { (scale) }\end{array}$} \\
\hline & & 7 & $\%$ & 5 & $\%$ & 3 & $\%$ & 1 & $\%$ & \\
\hline
\end{tabular}

Using gamma $\mathrm{Co}^{60}$ at $12 \mathrm{krad}$ dosage

\begin{tabular}{l|c|c|r|r|r|r|r|r|r|l}
\hline M2 & 22 & 1 & 4.55 & 4 & 18.18 & 11 & 50.00 & 6 & 27.27 & 3.00 \\
\hline M3 & 73 & 6 & 8.22 & 22 & 30.14 & 31 & 42.47 & 14 & 19.18 & 3.55 \\
\hline M4 & 479 & 43 & 8.98 & 165 & 34.45 & 185 & 38.62 & 87 & 18.16 & 3.69 \\
\hline M5 & 246 & 25 & 10.12 & 99 & 40.08 & 91 & 36.84 & 32 & 12.96 & 3.95 \\
\hline M6 & 166 & 19 & 11.45 & 81 & 48.80 & 57 & 34.34 & 9 & 5.42 & 4.33 \\
\hline M7 & 71 & 8 & 11.27 & 34 & 47.89 & 29 & 40.85 & 0 & & 4.41 \\
\hline M8 & 34 & 4 & 11.76 & 19 & 55.88 & 11 & 32.35 & 0 & & 4.59 \\
\hline M9 & 26 & 3 & 11.54 & 16 & 61.54 & 7 & 26.92 & 0 & & 4.69 \\
\hline M10 & 25 & 3 & 12.00 & 15 & 60.00 & 7 & 28.00 & 0 & & 4.68
\end{tabular}

Using gamma $\mathrm{Co}^{60}$ at $15 \mathrm{krad}$ dosage

\begin{tabular}{l|c|c|r|r|r|r|r|r|r|l}
\hline M2 & 27 & 2 & 7.41 & 5 & 18.52 & 5 & 18.52 & 15 & 55.56 & 2.56 \\
\hline M3 & 111 & 2 & 1.80 & 11 & 9.91 & 59 & 53.15 & 39 & 35.14 & 2.57 \\
\hline M4 & 432 & 8 & 1.85 & 55 & 12.73 & 254 & 58.80 & 115 & 26.62 & 2.80 \\
\hline M5 & 267 & 10 & 3.75 & 54 & 20.22 & 180 & 67.42 & 23 & 8.61 & 3.38 \\
\hline M6 & 379 & 12 & 3.17 & 102 & 26.91 & 265 & 69.92 & 0 & & 3.66 \\
\hline M7 & 132 & 14 & 10.61 & 74 & 56.06 & 44 & 33.33 & 0 & & 4.55 \\
\hline M8 & 173 & 17 & 9.83 & 105 & 60.69 & 51 & 28.48 & 0 & & 4.61 \\
\hline M9 & 121 & 12 & 9.92 & 76 & 62.81 & 33 & 28.70 & 0 & & 4.65 \\
\hline M10 & 52 & 5 & 9.62 & 33 & 63.46 & 14 & 26.92 & 0 & & 4.65 \\
\hline
\end{tabular}

${ }^{\mathrm{a}} G$ Mutant generation

According to quality characteristics shown in Table 11.5, mutant Tam Thom lines $\mathrm{T} 1$ and $\mathrm{T} 2$ have a very high rate of chalkiness of endosperm which is an obstacle in cross-breeding. However, T1 and T2 are not photosensitive to short-day light and have several other important characteristics such as maintenance of aroma of Tam Thom, closeness between grains, moderate susceptibility to leaf blast (caused by Pyricularia oryzae) and low amylose content. Mutant Tam Thom T1 line has brown-yellow colour of grain husk and aroma score of 4.1 which is nearly equal to the aroma score of Tam Thom Hai HauTT1. Tam Thom Hai HauTT1 is highly resistant to leaf blast, and Hoa Sua is an extra long and slender grain, very early maturing and semidwarf. These are the basic characteristics transferred into progenies to create specific characteristics of new rice varieties (Fig. 11.3).

In classical plant breeding, selection typically involves evaluating a breeding population for one or more traits at field trials. In pedigree breeding method, selection of desirable plants is made at early generations for traits of higher heritability. So, effective phenotypic screening will be less expensive for selection in large populations. These $\mathrm{F}_{2}$ populations were developed, and stringent phenotypic selection based on phenotypic preference (like early maturity, panicle length, grain shape, aroma, etc.) was carried out on segregating populations to obtain 


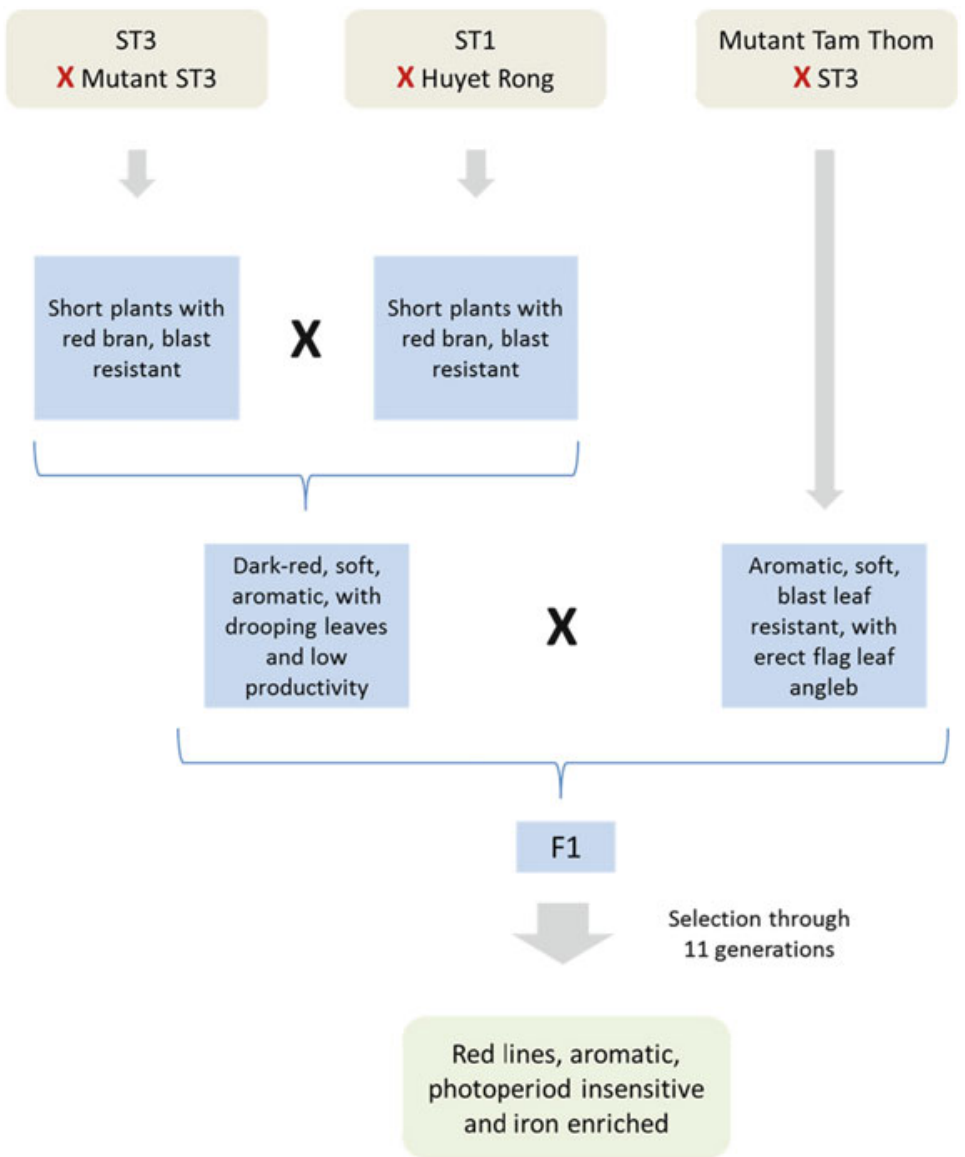

Fig. 11.2 Hybridization between five parents by cutting husks method. Crossing begins between ST3 and mutant ST3 (top left), ST1 and Huyet Rong (middle) and ST3 and Mutant Tam Thom $($ right). Resulting plants are phenotyped and plants with desired traits are selected (blue boxes). Hybridization of these materials is done and then is propagated through 11 generations to produce a line with the desired combination of traits (bottom box). Since the $\mathrm{F}_{2}$ population contains heterozygotes, and heterozygote and dominant homozygote are not easily distinguishable, crossing is continued. Strongly aromatic lines continued to separate highly into four groups such as strongly aromatic, medium aromatic, slightly aromatic and non-aromatic at early generations, and the separation decreased through propagation until traits are pure bred. The rate of strongly aromatic and aromatic lines increased from 1.79 to $8.04 \%$ of total aroma tested lines correlatively from $F_{2}$ generation to $F_{11}$ generation, and the mean aroma score of populations increased from 2.35 to 4.69 . To the $F_{11}$ generation, we have selected 9 strongly aromatic and 75 aromatic lines. Figure courtesy of Dr Joanna Jankowicz-Cieslak and Dr Bradley J. Till of the FAO/IAEA Joint Programme

agronomically desirable plants and reduce the population size. Selection of desirable plants is also similar in the next segregating populations until pure breeding lines are produced. 
11 Breeding New Aromatic Rice with High Iron Using Gamma Radiation and. . .

Table 11.3 The result of aromatic lines selected over segregating generations

\begin{tabular}{|c|c|c|c|c|c|c|c|c|c|c|}
\hline \multirow[b]{2}{*}{$\mathrm{G}^{\mathrm{a}}$} & \multirow{2}{*}{$\begin{array}{l}\text { Lines used } \\
\text { for aroma } \\
\text { testing }\end{array}$} & \multicolumn{8}{|c|}{ Aromatic scale } & \multirow{2}{*}{$\begin{array}{l}\text { Mean aroma } \\
\text { of } \\
\text { populations } \\
\text { (scale) }\end{array}$} \\
\hline & & 7 & $\%$ & 5 & $\%$ & 3 & $\%$ & 1 & $\%$ & \\
\hline
\end{tabular}

Separating generations of five parents (RED ST)

ST3/Mutant ST3//ST1/Huyet Rong/// Mutant Tam Thom T5/ST3

\begin{tabular}{l|l|r|r|r|r|r|r|r|r|l}
\hline F2 & 3120 & 56 & 1.79 & 312 & 10.00 & 1320 & 42.31 & 1432 & 45.90 & 2.35 \\
\hline F3 & 4651 & 74 & 1.59 & 501 & 10.77 & 1812 & 38.96 & 2064 & 44.38 & 2.26 \\
\hline F4 & 4551 & 79 & 1.74 & 513 & 11.27 & 2013 & 44.23 & 1946 & 42.76 & 2.44 \\
\hline F5 & 3656 & 65 & 1.78 & 451 & 12.34 & 1751 & 47.89 & 1389 & 37.99 & 2.56 \\
\hline F6 & 3541 & 79 & 2.23 & 564 & 15.93 & 2015 & 56.90 & 883 & 24.94 & 2.91 \\
\hline F7 & 3621 & 110 & 3.04 & 662 & 18.28 & 2068 & 57.11 & 781 & 21.57 & 3.06 \\
\hline F8 & 2893 & 211 & 7.29 & 711 & 24.58 & 1720 & 59.45 & 251 & 8.68 & 3.61 \\
\hline F9 & 2113 & 189 & 8.94 & 611 & 28.92 & 1142 & 54.05 & 171 & 8.09 & 3.77 \\
\hline F10 & 1723 & 162 & 9.40 & 752 & 43.64 & 743 & 43.12 & 66 & 3.83 & 4.17 \\
\hline F11 & 112 & 9 & 8.04 & 75 & 66.96 & 29 & 25.89 & 0 & 0 & 4.69 \\
\hline
\end{tabular}

${ }^{\mathrm{a}} G$ mutant generation

Table 11.4 The evaluation results of bioavailable zinc and bioavailable iron contents of the nine lines plus control

\begin{tabular}{l|l|l|l}
\hline No. & Name of lines & Bioavailable zinc content $(\mathrm{ppm})$ & Bioavailable iron content $(\mathrm{ppm})$ \\
\hline 1 & R110-755 & $21.2 \pm 2.1$ & $14.6 \pm 1.0$ \\
\hline 2 & R34RD-840 & $25.6 \pm 2.2$ & $24.8 \pm 1.9$ \\
\hline 3 & R35RD-869 & $21.1 \pm 1.7$ & $19.8 \pm 1.2$ \\
\hline 4 & R75-797 & $20.8 \pm 2.0$ & $21.8 \pm 1.1$ \\
\hline 5 & R76-696 & $21.0 \pm 1.8$ & $65.1 \pm 2.3$ \\
\hline 6 & R75-747 & $21.0 \pm 2.1$ & $15.7 \pm 1.2$ \\
\hline 7 & R51-723 & $24.5 \pm 1.9$ & $25.8 \pm 1.4$ \\
\hline 8 & R857-821 & $29.8 \pm 2.5$ & $44.3 \pm 2.2$ \\
\hline 9 & R8-786 & $23.7 \pm 1.6$ & $22.2 \pm 1.2$ \\
\hline 10 & Jasmine 85 & & $12.8 \pm 0.9$
\end{tabular}

Table 11.5 Agronomic characteristics of rice materials

\begin{tabular}{l|l|l|l|l|l}
\hline $\begin{array}{l}\text { Name of } \\
\text { parents }\end{array}$ & $\begin{array}{l}\text { Growth } \\
\text { duration } \\
\text { (days) }\end{array}$ & $\begin{array}{l}\text { Plant } \\
\text { height } \\
(\mathrm{cm})\end{array}$ & $\begin{array}{l}\text { Brown grain } \\
\text { length }(\mathrm{mm})\end{array}$ & $\begin{array}{l}\text { Reaction to brown } \\
\text { plant hoppers } \\
\text { (scale) }\end{array}$ & $\begin{array}{l}\text { Reaction to } \\
\text { leaf blast } \\
\text { (scale) }\end{array}$ \\
\hline Mutant T1 & 95 & $115 \pm 5.7$ & $7.0 \pm 0.2$ & 7 & 5 \\
\hline Mutant T2 & 99 & $101 \pm 3.2$ & $7.1 \pm 0.2$ & 7 & 5 \\
\hline $\begin{array}{l}\text { Tam Thom } \\
\text { Hai }\end{array}$ & 118 & $145 \pm 6.2$ & $5.6 \pm 0.2$ & 3 & 2 \\
\hline HauTT1 & 90 & $100 \pm 1.0$ & $7.8 \pm 0.1$ & 9 & 6 \\
\hline Hoa Sua & 90 & & &
\end{tabular}


Table 11.6 Quality characteristic of parents

\begin{tabular}{l|l|l|l|l|l|l}
\hline $\begin{array}{l}\text { Name } \\
\text { of } \\
\text { parents }\end{array}$ & $\begin{array}{l}\text { Weight of } \\
1000 \\
\text { grains } \\
\text { (gramme) }\end{array}$ & $\begin{array}{l}\text { Zero-scale } \\
\text { chalkiness } \\
\text { of } \\
\text { endosperm } \\
(\%)\end{array}$ & $\begin{array}{l}\text { Gelatinization } \\
\text { temperature } \\
\text { (scale) }\end{array}$ & $\begin{array}{l}\text { Amylose } \\
\text { content } \\
(\%)\end{array}$ & $\begin{array}{l}\text { Gel } \\
\text { consistency } \\
(\mathrm{mm})\end{array}$ & $\begin{array}{l}\text { Aroma } \\
\text { (scale) }\end{array}$ \\
\hline $\begin{array}{l}\text { Mutant } \\
\text { T1 }\end{array}$ & $19.6 \pm 0.3$ & $14.6 \pm 4.0$ & $6.6 \pm 0.5$ & $18.4 \pm 1.4$ & $71.5 \pm 1.9$ & $4.1 \pm 0.04$ \\
\hline $\begin{array}{l}\text { Mutant } \\
\text { T2 }\end{array}$ & $19.7 \pm 0.3$ & $22.4 \pm 2.4$ & $6.4 \pm 0.5$ & $19.5 \pm 0.9$ & $61.2 \pm 2.1$ & $3.4 \pm 0.04$ \\
\hline $\begin{array}{l}\text { Tam } \\
\text { Thom }\end{array}$ & $19.1 \pm 0.3$ & $97.6 \pm 1.1$ & $5.6 \pm 0.5$ & $16.9 \pm 0.4$ & $77.7 \pm 1.7$ & $4.4 \pm 0.04$ \\
$\begin{array}{l}\text { Hai } \\
\text { HauTT1 }\end{array}$ & & & & & & \\
\hline Hoa Sua & $24.1 \pm 0.3$ & $99.8 \pm 0.8$ & $5.7 \pm 0.2$ & $12.1 \pm 0.4$ & $60.2 \pm 3.5$ & $2.7 \pm 0.81$ \\
\hline
\end{tabular}

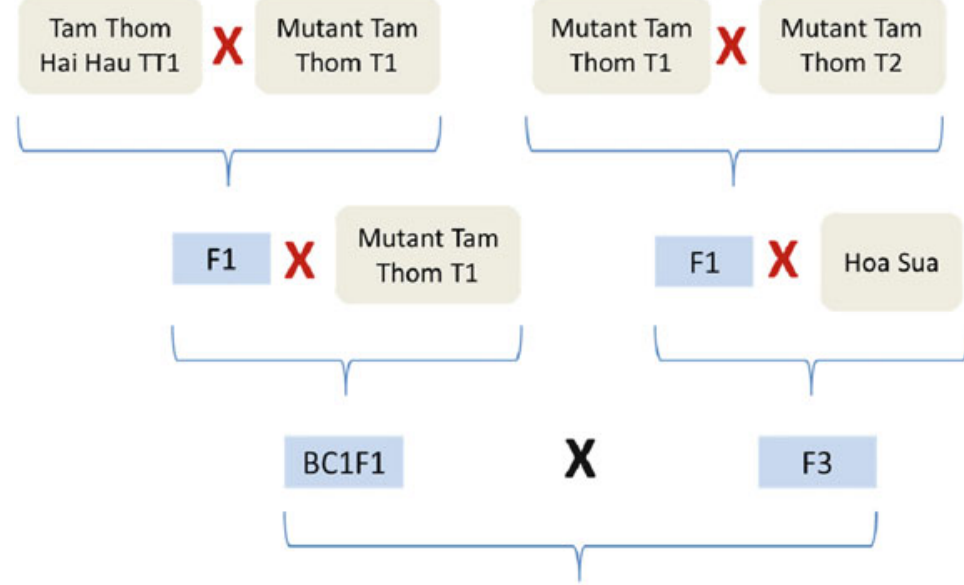

F1

ST19

Fig. 11.3 Crosses carried out to produce the variety ST19 using varieties and advanced mutant lines. Successive rounds of back- and outcrosses were carried out to create a line with combined characteristics. Figure courtesy of Dr Joanna Jankowicz-Cieslak and Dr Bradley J. Till of the FAO/IAEA Joint Programme 
Table 11.7 The result of aromatic lines selected over segregating generations

\begin{tabular}{|c|c|c|c|c|c|c|c|c|c|c|}
\hline \multirow[b]{2}{*}{$\mathrm{G}^{\mathrm{a}}$} & \multirow{2}{*}{$\begin{array}{l}\text { Lines used } \\
\text { for aroma } \\
\text { testing }\end{array}$} & \multicolumn{8}{|c|}{ Aromatic scale } & \multirow{2}{*}{$\begin{array}{l}\text { Mean aroma of } \\
\text { populations } \\
\text { (scale) }\end{array}$} \\
\hline & & 7 & $\%$ & 5 & $\%$ & 3 & $\%$ & 1 & $\%$ & \\
\hline
\end{tabular}

Separating generations of four parents (ST19)

TT1/2*Mutant Tam Thom T1///Hoa Sua/Mutant Tam Thom T2//Mutant Tam Thom T1

\begin{tabular}{l|r|r|r|r|r|r|r|r|r|l}
\hline F2 & 2527 & 56 & 2.22 & 817 & 32.33 & 1326 & 52.47 & 328 & 12.98 & 3.48 \\
\hline F3 & 427 & 17 & 3.98 & 151 & 35.36 & 208 & 48.71 & 51 & 11.94 & 3.63 \\
\hline F4 & 268 & 18 & 6.72 & 122 & 45.52 & 101 & 37.69 & 27 & 10.07 & 3.98 \\
\hline F5 & 333 & 30 & 9.01 & 168 & 50.45 & 130 & 39.04 & 5 & 1.50 & 4.34 \\
\hline F6 & 493 & 53 & 10.75 & 264 & 53.55 & 176 & 35.70 & 0 & & 4.50 \\
\hline F7 & 277 & 30 & 10.83 & 148 & 53.43 & 99 & 35.74 & 0 & & 4.50 \\
\hline
\end{tabular}

${ }^{\mathrm{a}} G$ segregating generation

In segregating populations of three combinations, we separated aroma into four groups such as strongly aromatic (score 7), moderately aromatic (score 5), lightly aromatic (score 3) and non-aromatic (score 1) (Table 11.7). Resulting lines from the hybridizations were further characterized for traits including amylose, 1000 grain weight and iron (Table 11.8).

\subsubsection{2-Acetyl-1-pyrroline Analysis in Aromatic Rice}

The high demand for fragrant rice cultivars in markets worldwide has driven the development of methods for quantifying 2-acetyl-1-pyrroline (2AP) and distinguishing fragrant and nonfragrant cultivars. The concentration of $2 \mathrm{AP}$ is controlled by a recessive gene for fragrance (fgr) mapped on rice chromosome 8. Methods for the determination of the volatile compounds in rice have schemes for collection, concentration, separation and quantification. The method of preference for the pre-concentration of flavour compounds is solid phase microextraction (SPME).

We determined the concentration of $2 \mathrm{AP}$ in 62 samples of rice grains (brown rice). The concentration of $2 \mathrm{AP}$ by SPME-GC analysis varied among seasons and ecological cultivated sites (Table 11.9).

\subsubsection{Molecular Screening for Aroma in Segregating Rice Lines}

To facilitate the selection of plants with improved aroma coming from natural alleles, we used a molecular marker strategy to test for the badh2 gene. Variations in this gene are thought to have major effects on rice aroma (Bradbury et al. 2005b; Chen et al. 2008). An example gel showing size polymorphism variation between aromatic and non-aromatic rice is shown in Fig. 11.4. 


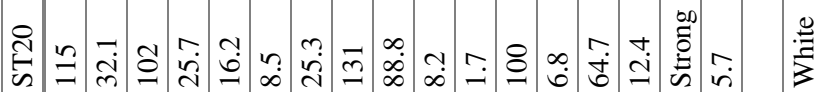

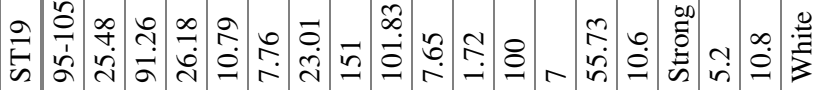

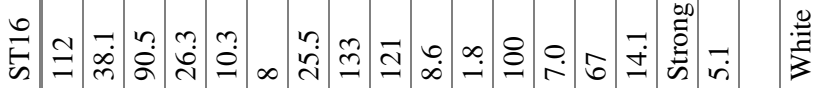
th

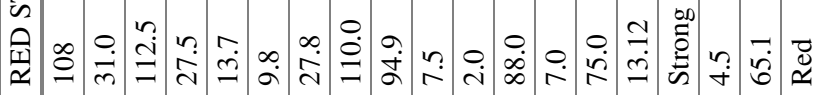
$\simeq$

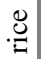


Table 11.9 The change of aroma content in aromatic rice among growing seasons

\begin{tabular}{l|l|l|l|l}
\hline \multirow{2}{*}{ Cultivated name } & \multicolumn{2}{l}{ 2AP content $(\mathrm{ppb})$} & \multicolumn{2}{l}{ Sensory test by smelling (scale) } \\
\cline { 2 - 5 } & Dry season & Wet season & Dry season & Wet season \\
\hline ST3 & 6.03 & 1.77 & 5.3 & 1.9 \\
\hline ST10 & 6.80 & 2.40 & 4.5 & 2.5 \\
\hline ST12 & 8.73 & 2.86 & 5.1 & 2.5 \\
\hline ST16 & 5.97 & 2.84 & 5.8 & 3.4 \\
\hline ST17 & 6.83 & 2.63 & 4.2 & 3.3 \\
\hline ST18 & 4.47 & 2.07 & 4.9 & 3.7 \\
\hline ST19 & 4.90 & 2.57 & 5.0 & 2.6 \\
\hline ST20 & 8.83 & 1.58 & 4.3 & 2.9 \\
\hline Jasmine 85 & 6.10 & 2.52 & 4.7 & 2.9 \\
\hline
\end{tabular}

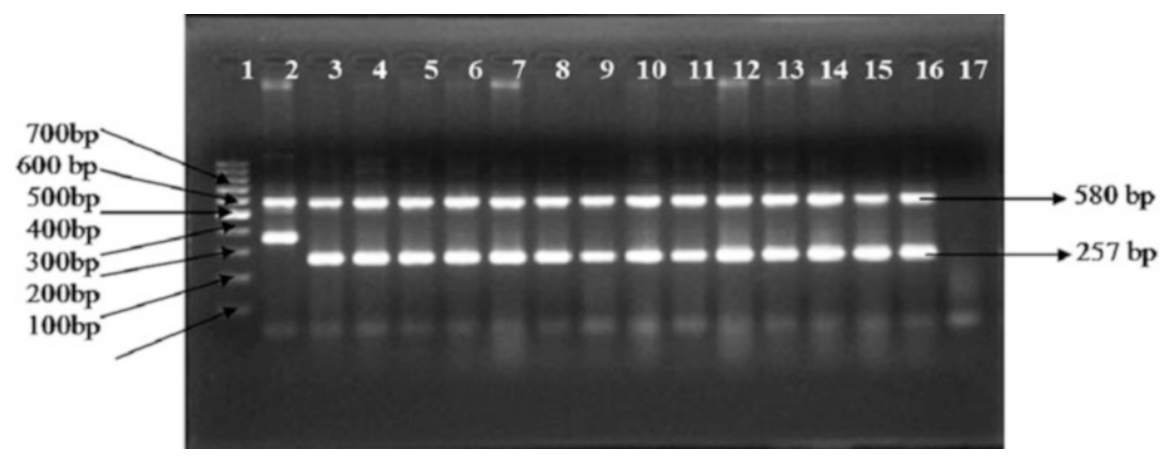

Fig. 11.4 PCR analysis of new aromatic rice varieties for the presence of aroma gene. Lanes 1, 100 bp ladder; 2, VD95-20 is non-aromatic; 3, ST10 is aromatic; 4, Red ST is aromatic; 5, 6, 7, Red 06 from $12 \mathrm{krad} ; 8,9,10$, Red 156 from $15 \mathrm{krad}$;1, 12, 13, Red 11 from mutant Zazu/Red ST; 14, 15, 16, aromatic rice 12 from mutant Zazu/ST10 and 17, water

\subsection{Conclusion}

Breeding aromatic rice varieties having high quality and yield in order to increase value and to serve increasing demand of customers domestically and for exportation is essential. Multiline crossing was carried out on mutant Tam Thom, and aroma improved rice varieties by using pedigree method. After a strict process of selection by qualitative and quantitative anticipated targets (life cycle, leaf and stem phenotypes, grain dimensions, aroma), we have selected aromatic rice varieties named ST16, ST19 and ST20. These varieties have growth duration of 95-115 days, improved phenotype (plant height of $102 \mathrm{~cm}$, strongly tillering) with actual yield higher than $5 \mathrm{ton} /$ ha and high-quality grain length $>7.5 \mathrm{~mm}$, slender grain, non-chalkiness of endosperm and low amylose content. Their grains are of high quality so they have high economic value.

Aroma in 20 Vietnamese local aromatic rice varieties (19 varieties of Tam group in the north of Vietnam and Nang Thom Cho Dao in the south of Vietnam) and Red 
06, Red 156, Red 11, aromatic rice 12, Red ST, ST16, ST19 and ST20 are explained by the badh2.1 allele. Aroma sensory and 2AP content in the dry season were higher than in the wet season. Rice aroma was segregating in before the establishment of pure-bred lines necessitating phenotypic and genotypic screening of material. Breeding would be further aided through establishing the interrelated scale between aroma scale and 2AP content. The strategy of mutant generation and selection and hybridization with accessions harbouring natural alleles allowed us to combine novel and existing traits to create new rice varieties. The methods can be adapted for other breeding objectives in rice and other seed-propagated crops.

Acknowledgements Funding for this work was provided by the Food and Agriculture Organization of the United Nations and the International Atomic Energy Agency through their Joint FAO/IAEA Programme of Nuclear Techniques in Food and Agriculture through Research Contract No. 15544 of IAEA Coordinated Research Project D24012 and by the Soc Trang people's committee, Vietnam.

Open Access This chapter is distributed under the terms of the Creative Commons AttributionNoncommercial 2.5 License (http://creativecommons.org/licenses/by-nc/2.5/) which permits any noncommercial use, distribution, and reproduction in any medium, provided the original author (s) and source are credited.

The images or other third party material in this chapter are included in the work's Creative Commons license, unless indicated otherwise in the credit line; if such material is not included in the work's Creative Commons license and the respective action is not permitted by statutory regulation, users will need to obtain permission from the license holder to duplicate, adapt or reproduce the material.

\section{References}

Bradbury LMT, Henry RJ, Jin Q, Russell F, Reinke RF, Waters DLE (2005) A perfect marker for fragrance genotyping in rice. Mol Breed 16(4):279-283

Buttery RG, Ling LC, Juliano BO, Turnbaugh JG (1983) Cooked rice aroma and 2-AP. J Agric Food Chem 31(4):823-826

Chen CW, Cheng HH (2006) A rice bran oil diet increases LDL-receptor and HMG-CoA reductase mRNA expressions and insulin sensitivity in rats with streptozotocin/nicotinamide-induced type 2 diabetes. J Nutr 136(6):1472-1476

Chen S, Yang Y, Shi W, Ji Q, He F, Zhang Z, Cheng Z, Liu X, Xu M (2008) Badh2, encoding betaine aldehyde dehydrogenase, inhibits the biosynthesis of 2-Acetyl-1-Pyrroline, a major component in rice fragrance. Plant Cell 20(7):1850-1861

Efferson JNE (1985) Rice quality in the world market. In: IRRI (ed) Rice grain quality and marketing. IRRI, Manila, pp. 1-13

Kovach MJ, Calingacion MN, Fitzgerald MA, McCouch SR (2009) The origin and evolution of fragrance in rice (Oryza sativa L.). Proc Natl Acad Sci USA 106(34):14444-14449

Liang J, Ha BZ, Han L, Nout MJR, Hamer RJ (2006) Iron, zinc and phytic acid content of selected rice varieties from China. J Sci Food Agric 87(3):504-510

MVD (2016) Mutant Variety Database from http://mvd.iaea.org/

Picó Y, Fernández M, Ruiz MJ, Font G (2007) Current trends in solid-phase-based extraction techniques for the determination of pesticides in food and environment. J Biochem Biophys Methods 70(2):117-131 
Sakthivel K, Shobha Rani N, Manish K, Pandey MK, Sivaranjani AKP, Neeraja CN, Balachandran SM, SheshuMadhav M, Viraktamath BC, Prasad GSV, Sundaram RM (2009) Development of a simple functional marker for fragrance in rice and its validation in Indian Basmati and non-Basmati fragrant rice varieties. Mol Breed 24(2):185-190

Shi W, Yang Y, Chen S, Xu M (2008) Discovery of a new fragrance allele and the development of functional markers for the breeding of fragrant rice varieties. Mol Breed 22:185-192

Sood BC, Siddiq EA (1978) A rapid technique for scent determination in rice. Indian J Genet Plant Breed 38(2):268-271

Soria AC, Sanz J, Martinez-Castro I (2009) SPME followed by GC-MS: a powerful technique for qualitative analysis of honey volatiles. Euro Food Res Technol 228(4):579-590

Stashenko EE, Martínez JR (2007) Sampling volatile compounds from natural products with headspace/solid-phase micro-extraction. J Biochem Biophys Methods 70(2):235-242

Tran T, Hoa C, Nguyen T, Phong L (2004) Effect of milling technology on iron content in rice grains of some leading varieties in the Mekong Delta. Omonrice 12:38-44

Yoshihashi T (2002) Quantitative analysis on 2-AP of an aromatic rice by Stable Isotope Dilution method and model studies on Its formation during cooking. J Food Sci 67(2):619-622

Yoshihashi T, Nguyen TTH, Kabaki N (2004) Area dependency of 2-Acetyl-1-Pyrroline content in an aromatic rice variety, Khao Dawk Mali 105. Jpn Int Res Cent Q 38(2):105-109 